\title{
The estimation of mean potential duration in endocrine myopathy
}

\author{
D. A. H. YATES ${ }^{1}$ \\ From the Department of Medicine, Hammersmith Hospital, London
}

Weakness and wasting of muscle, particularly affecting the limb girdles, trunk, and face, have been reported in several endocrine disturbances. In Cushing's syndrome muscle weakness and fatigue were reported as a frequent complication by Cushing (1932) and by Plotz, Knowlton, and Ragan (1952). Although thyrotoxic myopathy was once thought to be unusual, Hed, Kirstein, and Lundmark (1958) reported 20 cases and Gimlette (1959) found weakness and electromyographic features of myopathy in 23 of 40 unselected thyrotoxic patients. Myopathy has complicated therapy with a variety of corticosteroid preparations including cortisone (Perkoff, Silber, Tyler, Cartwright, and Wintrobe, 1959), prednisone (Harman, 1959), triamcinalone (Williams, 1959), dexamethasone (Golding, Murray, Pearce, and Thompson, 1961), fluorocortisone (MacLean and Schurr, 1959), and corticotrophin (Yates, 1963).

The main electrodiagnostic change that can be detected in a myopathy is that individual potentials are shorter in duration, smaller in amplitude, and a greater proportion are polyphasic than normal. These changes have the effect of increasing the high frequency component in the electrical activity produced on volition and this increase can be detected audibly on a loudspeaker or by electronic frequency analysis. However, frequently these changes are only detectable in some areas of a myopathic muscle while other areas of the same muscle seem normal. A quantitative estimate of these changes is thus desirable but this is difficult to obtain from frequency analysis. Kugelberg (1949) showed that the mean spike duration of muscle potentials was shortened in myopathic disorders and Buchtal and Pinelli (1953) showed shortening of total potential duration in polymyositis. This method produces a quantitative result permitting serial examinations to be compared.

The present study was performed to ascertain the value of the estimation of the mean potential duration as an index of myopathic involvement in some endocrine disturbances.

'Present address: St. Thomas's Hospital, London, S.E.1.
METHODS

EQUIPMENT A standard Medelec two-channel electromyograph unit (type M.S.C.3) was used. The differential amplifiers have an input impedance of 2 megohms with 50 picafarads in parallel. The in-phase rejection ratio measured at the input terminals is greater than 1,000:1 at 1 kilocycle per second. With a time constant of $0 \cdot 1 \mathrm{sec}$, measured $3 \mathrm{~d}$ B points were at $1.6 \mathrm{c} / \mathrm{s}$ and 5 kilocycles per second. Concentric needle electrodes were used in which the cannula (external diameter $0.45 \mathrm{~mm}$.) and central core (diameter $0.12 \mathrm{~mm}$.) were of stainless steel with an intermediate insulation of more than $100 \mathrm{meg}-$ ohms provided by Araldite. The elliptical leading-offo area of the core tip was $0.34 \mathrm{sq} . \mathrm{mm}$. and the electrodesi had an impedance of approximately 100 kilohms (pre $\frac{\widehat{P}}{\mathrm{D}}$ dominantly capacitative) measured at 10 millivolts and 2 $100 \mathrm{c} / \mathrm{s}$ in isotonic saline. The time calibration was provided by a 1 kilocycle per second oscillator with a $10: 1$ frequency divider giving a ruler-type time scale with 10 and $1 \mathrm{msec}$. divisions.

TECHNIQUE With the patient making a minimal effort two electrodes were inserted in the deltoid and adjusted until individual spike potentials arising from a flat baseline were displayed on both channels. At a sweep duration of $30 \mathrm{msec}$., five or more single sweep photographs were taken and then each electrode was moved to record other potentials in 10 different positions so that at least 20 different potentials were available for measurement which, as Buchthal and Pinelli (1953) have shown, is the minimum number for obtaining a satisfactory estimate of the mean duration.

The typical configuration of normal and myopathic potentials is shown in Fig. 1, the spike phase being followed by a gently curved tail. The duration was measured, directly on the film record, from the onset of the potential to the point where the trace returns to the baseline. For accurate measurements the baseline must be flat and each potential recorded at least twice to verify its shape. The $\mathbf{2 0}$ or more different potentials were measured in this way and then the mean duration was calculated. This recording took about 15 minutes which left ample time to perform routine electrodiagnostic procedures.

To exclude observer bias a number of records from controls and patients were remeasured with the identifying labels removed and the results did not vary from the original estimation by more than $5 \%$. A similar agree- 

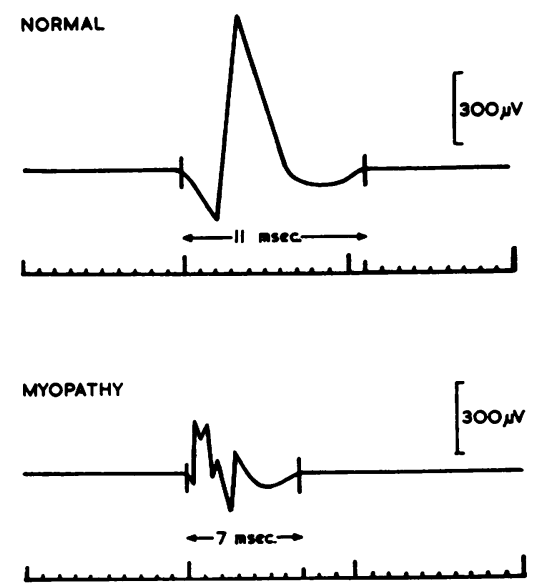

FIG. 1. Diagrammatic representation of individual muscle potentials recorded at minimal volition to show technique of duration measurement. Time scale 1 and $10 \mathrm{msec}$.

ment was found when different needles with the same specifications were used in a repeat examination of the same subject.

\section{RESULTS}

CONTROLS The normal range of the mean potential duration in the deltoid for the equipment used was established from 28 subjects of different ages with no evidence of neuromuscular disease. The results are shown in Fig. 2, in which it can be seen that there is

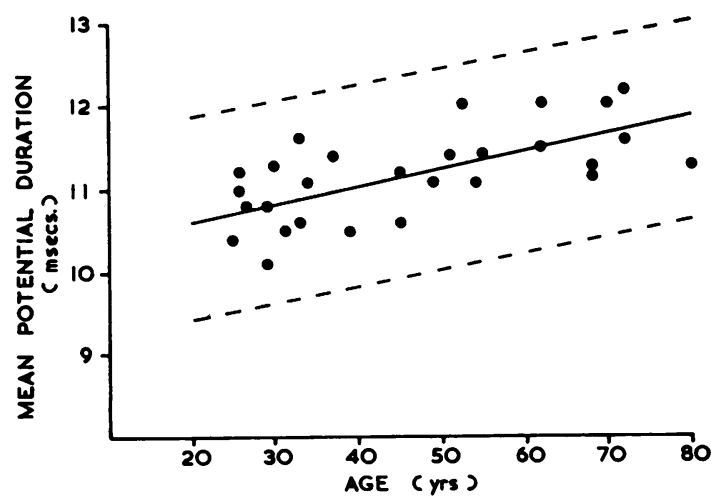

FIG. 2. Relation between age (in years) and mean potential duration (M.P.D.) in 28 control subjects. Equation of regression line is: M.P.D. $=0.020 \times$ age +10.21 . Broken lines are 3 standard deviations $(3 \times 0.40$ msec. $=$ $1.20 \mathrm{msec}$ ) either side of the regression line; these are taken as the normal limits. a gradual increase with age (correlation coefficient $=$ $0.64: \mathrm{P}<0.01$ ). The normal range was taken to be three standard deviations either side of the regression line.

THYROTOXICOSIS Ten patients (Fig. 3) were studied in which the diagnosis was proven by radioactive iodine studies. Seven of these showed weakness and in all the mean potential duration was shorter than the normal range. In three, re-examined after successful treatment and return of normal muscle power, the mean potential duration had increased into the normal range. Three patients had no detectable weakness and in these the mean potential duration was in the normal range.

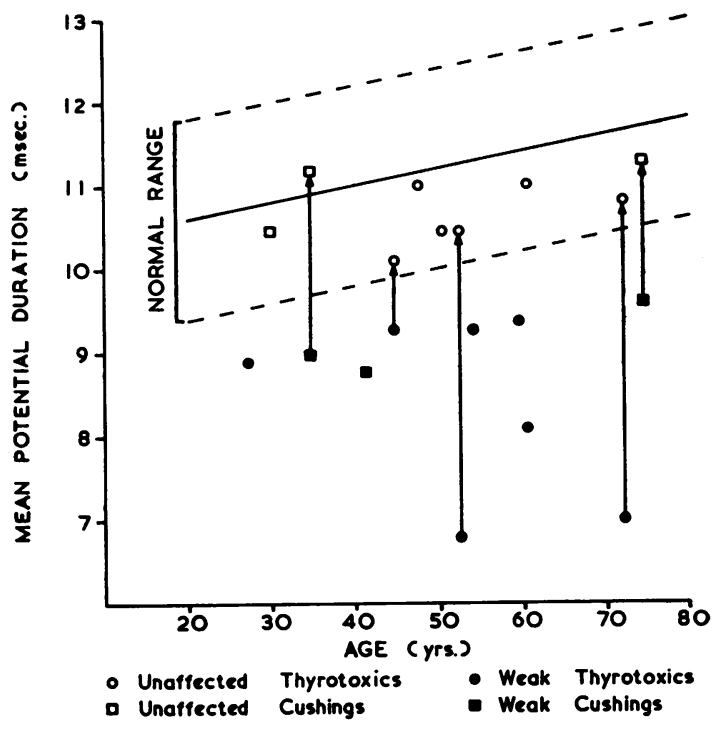

FIG. 3. Mean potential duration in deltoid muscle in 10 cases of thyrotoxicosis and four cases of Cushing's syndrome showing correlation between clinical weakness and shortening of mean potential duration. Upward pointing arrows indicate return of normality following successful treatment.

CUSHING'S SYNDROME In four patients (Fig. 3) the diagnosis was confirmed by the mean level of free plasma cortisol and the absence of a diurnal rhythm (Mattingly, 1962), the 24-hour urinary output of ketogenic steroids and the failure of dexamethasone to suppress this output.

Three patients had a clinical myopathy and the mean potential duration was shorter than the normal range. In two of these it increased to the normal range following successful treatment and the return of normal muscle power. It was normal in one patient who showed no weakness. The following illustrative case may be cited: 
TABLE

CASES STUDIED BEFORE AND DURING

CORTICOSTEROID THERAPY

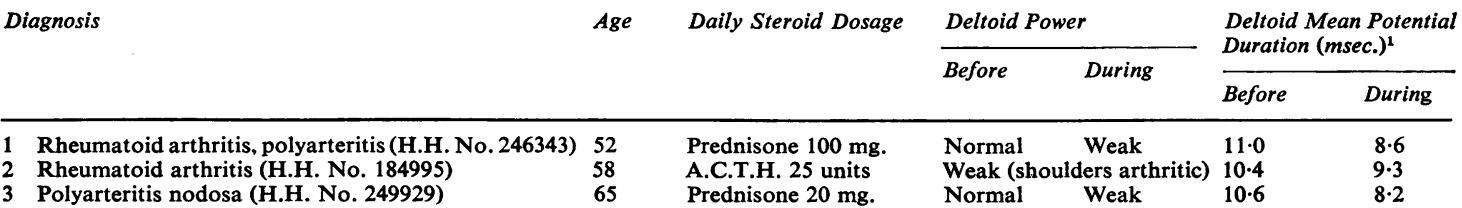

${ }^{1}$ Normal range for age group $10.0-12.8 \mathrm{~m} \mathrm{sec}$.

A woman aged 35 (H.H. No. 261065) under the care of Professor Russell Fraser had noticed spontaneous bruising, increasing fullness of the face, and shortness of breath on exertion for 12 years and for some time before admission she had had difficulty in climbing stairs and in doing her hair. A diagnosis of Cushing's syndrome was confirmed by the finding of a mean free plasma cortisol level of $33 \mathrm{mg} . \%$ (normal range 6 to $24 \mathrm{mg}$. \%) which showed no diurnal rhythm or suppression by dexamethasone. A small adrenal adenoma was removed at laparotomy after which free plasma cortisol was undetectable. On admission there was marked weakness and wasting of both deltoids and the mean potential duration was $8.6 \mathrm{msec}$. (normal range $9 \cdot 7-12.2 \mathrm{msec}$.). Three months post-operatively the deltoid power was normal and the mean potential duration had risen to $11 \cdot 2 \mathrm{msec}$.

CORTICOSTEROID THERAPY Three cases were studied before and three months after commencing treatment with corticosteroids and are summarized in the Table. Two of these developed moderate weakness but muscle power could not be reliably assessed in case 2 because both shoulders were involved by rheumatoid arthritis: in all the mean potential duration fell from the normal range during treatment.

In case 3 successive readings were made on the third, fifth, seventh, tenth, and 77th days of treatment with $20 \mathrm{mg}$. of prednisone daily and the readings were $11.0,10.6,10.5,10.7$, and $8.2 \mathrm{msec}$. respectively. The first four estimates demonstrate the reproducibility of the method and the last that, as expected, steroid myopathy takes some time to develop.

\section{DISCUSSION}

Buchthal, Guld, and Rosenfalck (1954) have shown that the type of electrodes used (unipolar, concentric, or bipolar), its leading-off area, and its impedance relative to the input impedance of the amplifier and the frequency response of the amplifier all exert an effect on the total duration of the recorded muscle potentials. These authors also showed that above $37^{\circ} \mathrm{C}$. the potential duration decreased by approxi- mately $10 \%$ per degree of rise in the intramuscular temperature. Because of the influence of these factors, and possibly of others, it is essential in any study of muscle potential duration to establish a normal range for the particular equipment in use and for the individual muscles being studied. Examinations should be performed under standard temperature conditions and if the patient is febrile the results must be adjusted. Because of the patchiness of myopathic changes it is important that potentials should be recorded from as many regions of the muscle as possible. The technique used in the present study represents a compromise between the need for wide exploration and the need to avoid undue discomfort for the patient who might be deterred from undergoing repeated examinations. Reproducible results were obtained which correlated well with the clinical findings and it was foundo possible to detect both the development and the recovery of a myopathy.

Müller and Kugelberg (1959) showed shortening of potential duration, particularly in the proximal limb muscles, in five cases of myopathy in Cushing's syndrome but none of their patients regained normal muscle power after treatment. Sanderson and Adey (1952) showed shortening of potential duration in two cases of thyrotoxic myopathy and return to normal in one of them after treatment. The findings of Sanderson and Adey are confirmed in the present study and in addition it has been shown that the myopathy of Cushing's syndrome is reversible.

The shortening of potential duration in myopathy is probably an expression of the reduction in the number of functioning fibres in the motor unit, which has been demonstrated histologically, although the mechanism of this is still not certain. This change is not specific and there is not yet any method of distinguishing electrodiagnostically between the various causes. The three conditions described here share a common feature in an increased catabolism of body protein; it is thus possible that the primary muscular abnormality may be a loss or change of the muscle proteins. 
SUMMARY

The mean potential duration in the deltoid was measured in 17 patients with endocrine disturbances, comprising 10 cases of thyrotoxicosis, four cases of Cushing's syndrome, and three cases receiving corticosteroid therapy.

The mean potential duration correlated well with the clinical states of the patients, being shorter than the normal range in 13 cases with a clinical myopathy and normal in four cases without weakness. In five myopathic patients, re-examined after successful treatment of their endocrine disturbance had restored normal muscle power, the mean potential duration increased into the normal range.

This work was performed during the tenure of a Medical Research Council fellowship which is gratefully acknowledged. I am indebted to Professor Russell Fraser and Professor E. G. L. Bywaters for allowing me to study their patients and to Mr. M. P. Curwen of St. Bartholomew's Hospital for statistical advice.

\section{REFERENCES}

Buchthal, F., and Pinelli, P. (1953). Neurology (Minneap.), 3, 424. -, Guld, C., and Rosenfalck, P. (1954). Acta physiol. scand., 32, 200. Cushing, H. (1932). Johns Hopk. Hosp. Bull., 50, 137.

Gimlette, T. M. D. (1959). Brit. med. J., 2, 1143.

Golding, D. N., Murray, S. M., Pearce, G. W., and Thompson, M. (1961). Ann. phys. Med., 6, 171.

Harman, J. B. (1959). Lancet, 1, 887.

Hed, R., Kirstein, L., and Lundmark, C. (1958). J. Neurol. Neurosurg. Psychiat., 21, 270.

Kugelberg, E. (1949). Ibid., 12, 129.

MacLean, K., and Schurr, P. H. (1959). Lancet, 1, 701.

Mattingly, D. (1962). J. clin. Path., 15, 374.

Müller, R., and Kugelberg, E. (1959). J. Neurol. Neurosurg. Psychiat., 22, 314.

Perkoff, G. T., Silber, R., Tyler, F. H., Cartwright, G. E. and Wintrobe M. M. (1959). Amer. J. Med., 26, 898.

Plotz, C. M., Knowlton, A. I., and Ragan, C. (1952). Ibid., 13, 597. Sanderson, K. V., and Adey, W. R. (1952). J. Neurol. Neurosurg. Psychiat., 15, 200.

Williams, R. S. (1959). Lancet, 1, 698.

Yates, D. A. H. (1963). Ann. rheum. Dis. Vol. 22. In press. 